\title{
The Role of Mutations on Genes AKT1, PTEN, GPC3, PIK3CA, In Proteus Syndrome
}

ISSN: 2576-9200

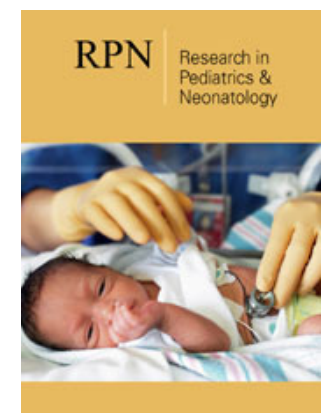

*Corresponding author: Shahin Asadi, Division of medical genetics and molecular pathology research, Harvard University, Boston children hospital, USA

Submission: 眥 February 18, 2020

Published: 制February 25, 2020

Volume 4 - Issue 3

How to cite this article: Shahin Asadi. The Role of Mutations on Genes AKT1, PTEN GPC3, PIK3CA, In Proteus Syndrome. Res Pediatr Neonatol. 4(3).RPN.000586.2020. DOI: $10.31031 /$ RPN.2020.04.000586

\section{Copyright $₫$ Shahin Asadi}

This article is distributed under the terms of the Creative Commons Attribution 4.0 International License, which permits unrestricted use and redistribution provided that the original author and source are credited.

\section{Shahin Asadi*}

Director of the Division of medical genetics and molecular optogenetic research, Medical Genetics-Harvard University

\section{Abstract}

Proteus syndrome is a rare condition that can be loosely categorized as a hamartomatous disorder. It is a complex disorder with multisystem involvement and great clinical variability. Once thought to have neurofibromatosis, Joseph Merrick (also known as "the elephant man" and studied by Treves in the 19th century) is now, in retrospect, thought by clinical experts to actually have had Proteus syndrome. This condition is characterized by various cutaneous and subcutaneous lesions, including vascular malformations, lipomas, hyperpigmentation, and several types of nevi.

Keywords: Proteus syndrome; Rare disease; Neurofibromatosis; Hamartomatous; AKT1; PTEN; GPC3; PIK3CA; Genes

\section{Overview of Proteus Syndrome}

Proteus syndrome is a rare genetic disorder, also known as wide man's syndrome, that is associated with overgrowth of various body tissues, including excessive skin growth, abnormal bone growth, and more than half of the body's tumor. Proteus syndrome is highly variable and derives from the name of one of the ancient Greek gods, Proteus, who was the god of the seas and could transform himself constantly [1].

\section{Signs and symptoms of proteus syndrome}

Proteus syndrome may affect the bones, connective tissue, adipose tissue, skin, central nervous system and internal organs (viscera). People with Proteus Syndrome may experience a wide range of complications including: skeletal abnormalities, benign and malignant tumors, blood vessel abnormalities, pulmonary diseases, and specific vesicular skin lesions. In some patients, Proteus Syndrome may also be life threatening due to abnormal blood clotting and can cause deep vein thrombosis and pulmonary embolism. The symptoms and severity of Proteus Syndrome vary from person to person. In some cases, the affected person may manifest only a few mild and mild symptoms of Proteus Syndrome, in which case it will be very difficult to diagnose. Most people affected by Proteus Syndrome do not show any significant symptoms at birth. However, some Proteus Syndrome sufferers may manifest excess brain development at birth. Excessive body growth in Proteus Syndrome usually begins between the ages of 6 and 18 months. Certain affected areas of the body in Proteus Syndrome vary greatly from disease to disease Figures 1-7. Bones, connective tissue, and adipose tissue are the most common areas of the body affected by Proteus Syndrome [1,2]. Excessive growth associated with Proteus Syndrome is irregular and disproportionate, affecting only one leg on one side of the body, for example. Excessive bone growth (bone protrusion) may affect the skull, the long bones of the hands and feet. The spine may also be affected by Proteus Syndrome and cause abnormal curvature of the spine in the form of scoliosis. Bone overgrowth may also affect the joints and limit joint movement [1,3]. In childhood, people with Proteus Syndrome may develop abnormal skin conditions, including over-adipose tissue in the limbs. In some patients with Proteus Syndrome, benign tumors of adipose tissue (lipoma) may be seen. In addition, overgrowth of adipose tissue in some individuals with Proteus Syndrome may cause chest atrophy. Children with Proteus Syndrome may develop wart or epidermal skin lesions on their skin, which are usually dark brown or black. Epidermal and connective tissue moles may be present in patients with Proteus Syndrome from birth. It is a slow-growing skin lesion that often occurs in the foot and is rarely present in the hand [1,4]. Various blood 
vessel abnormalities are common in Proteus syndrome that affects the capillaries, veins and lymph vessels. People with Proteus
Syndrome may be at risk for blood clots in the legs, known as deep vein thrombosis (DVT).

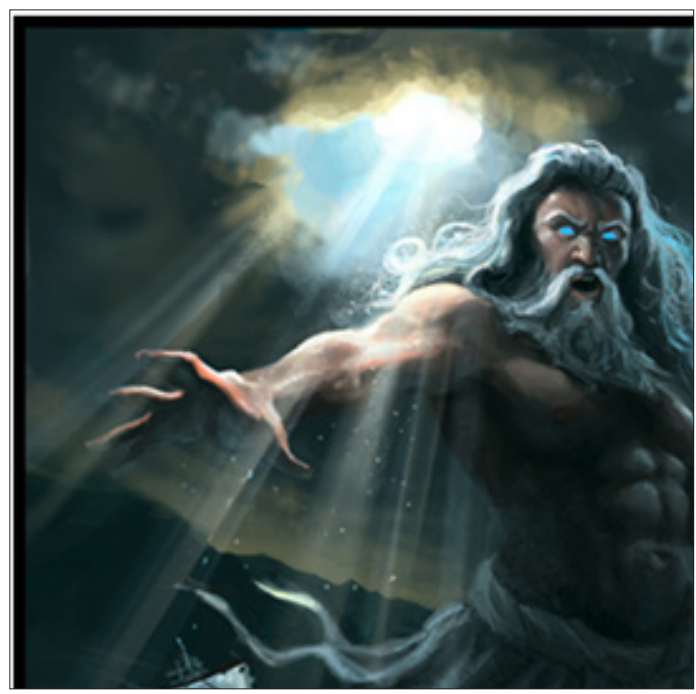

Figure 1: Schematic view of Proteus, the god of the seas in ancient Greece.

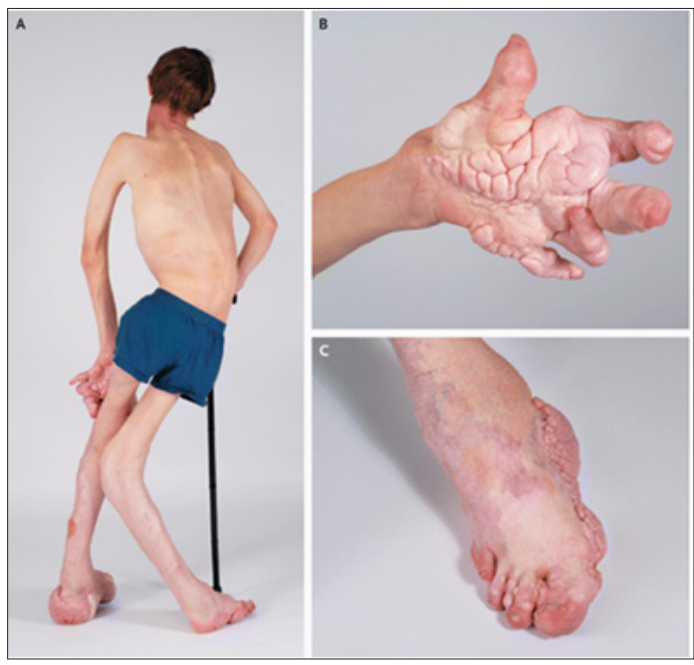

Figure 2: Image of a person with Proteus Syndrome, with over-growth of bones and adipose tissue and connective tissue and abnormal spine curvature (scoliosis).

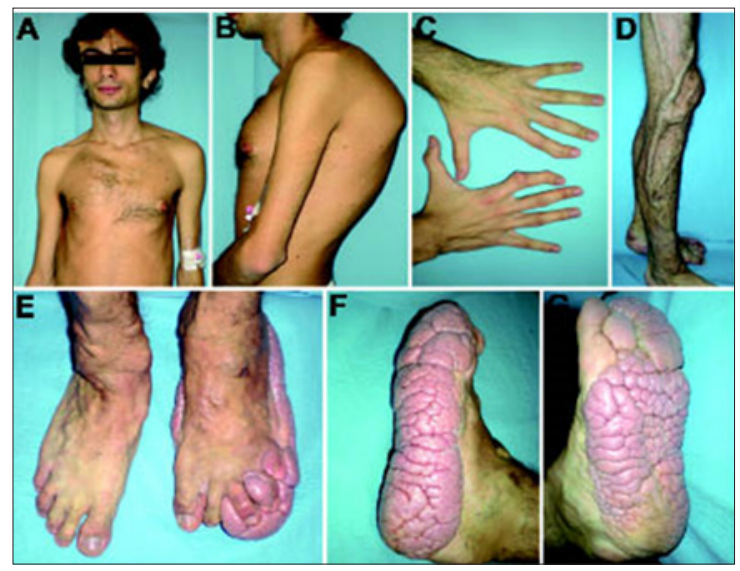

Figure 3: Other images of Proteus Syndrome sufferers. 


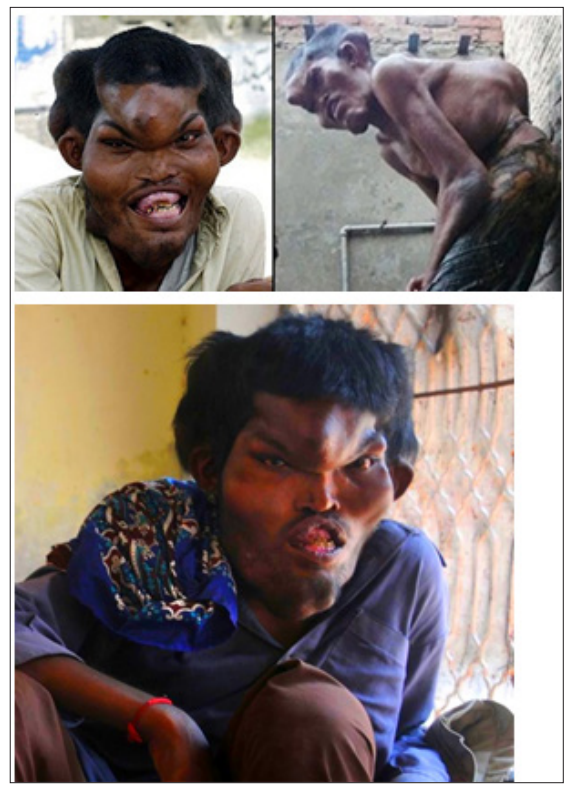

Figure 4: Picture of a man with Proteus Syndrome with a very abnormal limb shape.

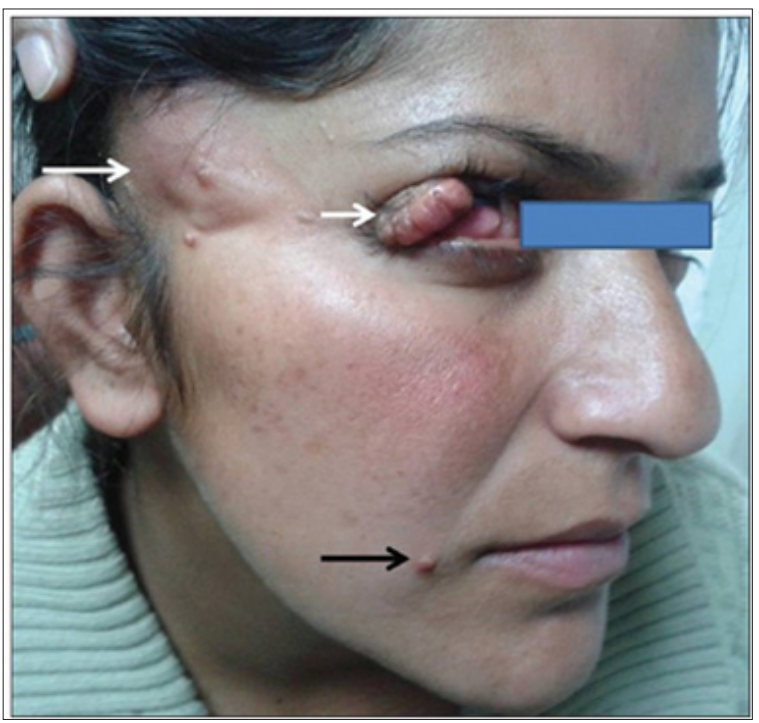

Figure 5: Picture of a woman with Proteus Syndrome with benign (dermoid) tumors in the eye.

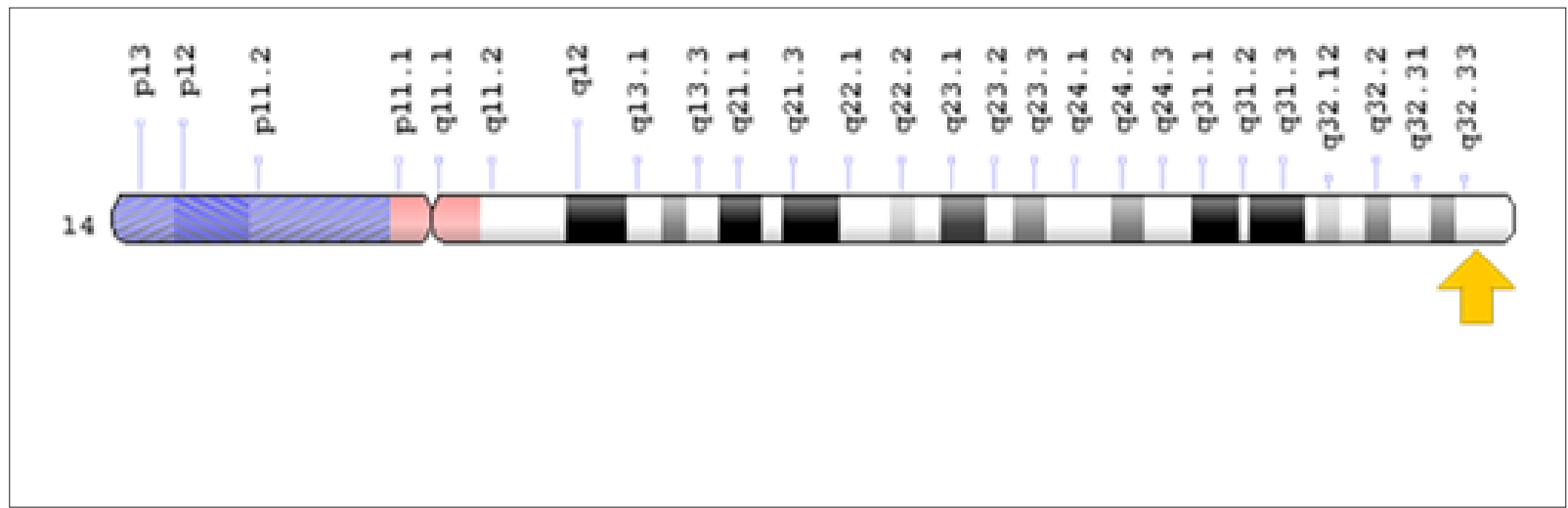

Figure 6: Schematic view of chromosome 14 where the AKT1 gene is located on the long arm of chromosome $14 \mathrm{q} 32.33$. 


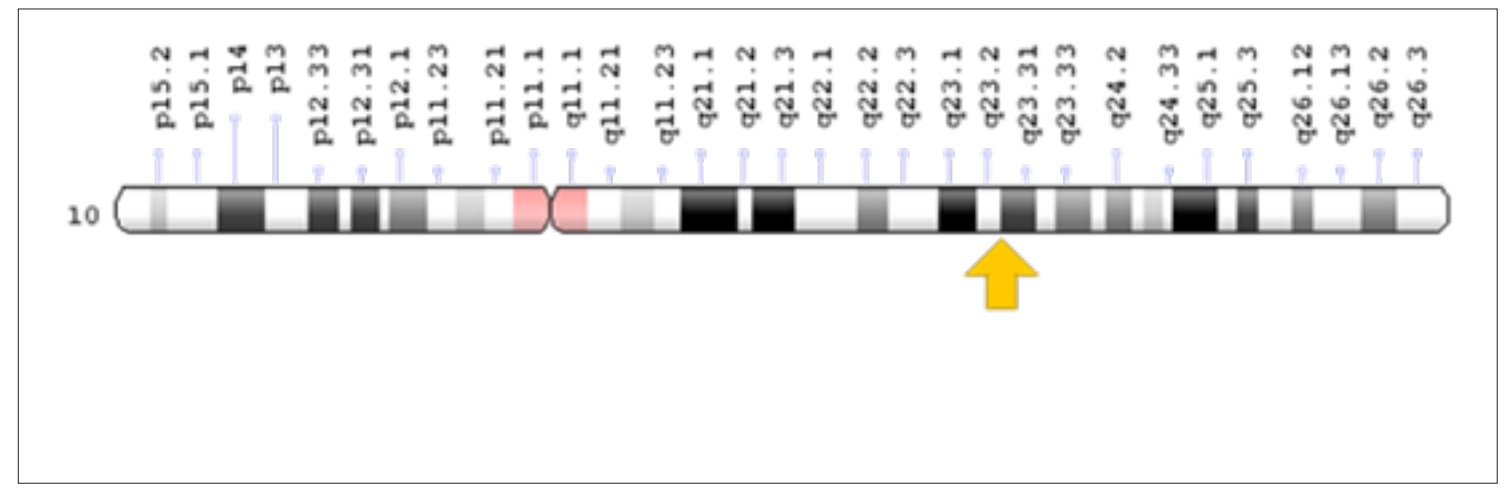

Figure 7: Schematic overview of chromosome 10 where the PTEN gene is located on the long arm of chromosome $10 \mathrm{q} 23.31$.

Therefore, patients with Proteus Syndrome may experience pain in their legs, and the blood vessels in their legs swell and enlarge and are clearly visible. Also, in some patients with Proteus Syndrome, deep vein thrombosis may progress to blood flow to the lungs and cause pulmonary embolism. Pulmonary embolism can cause shortness of breath, sudden chest pain, fatigue, or life-threatening complications such as hypertension from the pulmonary artery Figures 8-10. Other additional findings that may occur in Proteus Syndrome include abnormal enlargement of internal organs such as the spleen, thymus, colon and other tissues $[1,5]$. People with Proteus Syndrome are also susceptible to a wide range of tumors, most of them benign. Most tumors associated with Proteus Syndrome include: cystadenoma on both sides of the ovary, a group of monomorphic adenoma and meningioma salivary gland tumors [1,6] Less common findings in Proteus Syndrome include central nervous system abnormalities such as hyperextension of the brain (hemigalencephaly). In some cases, intellectual disability and seizures have also been reported in patients with Proteus Syndrome. Patients with Proteus Syndrome may also have distinct facial features such as: long or long facial size, eyelid clefts, eyelid ptosis, short nasal bridge, wide and wide nose, and long and long head (dulcephalus). The cause of the relationship between neurological and facial disorders in Proteus syndrome is still unknown [1,7]. Some people with Proteus Syndrome may develop cystic lung disease, kidney or genitourinary disorders, eye disorders such as lupus (strabismus) or benign cysts or tumors in the eye (epileptic or dermoid cysts) [1,8].

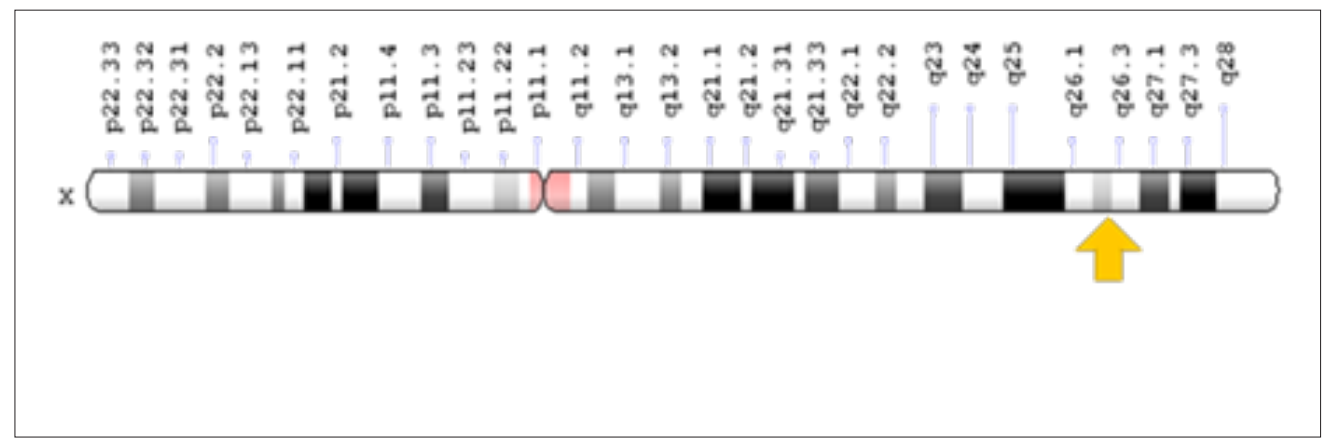

Figure 8: Schematic view of the sex chromosome X where the GPC3 gene is located on the long arm of this chromosome Xq26.2.

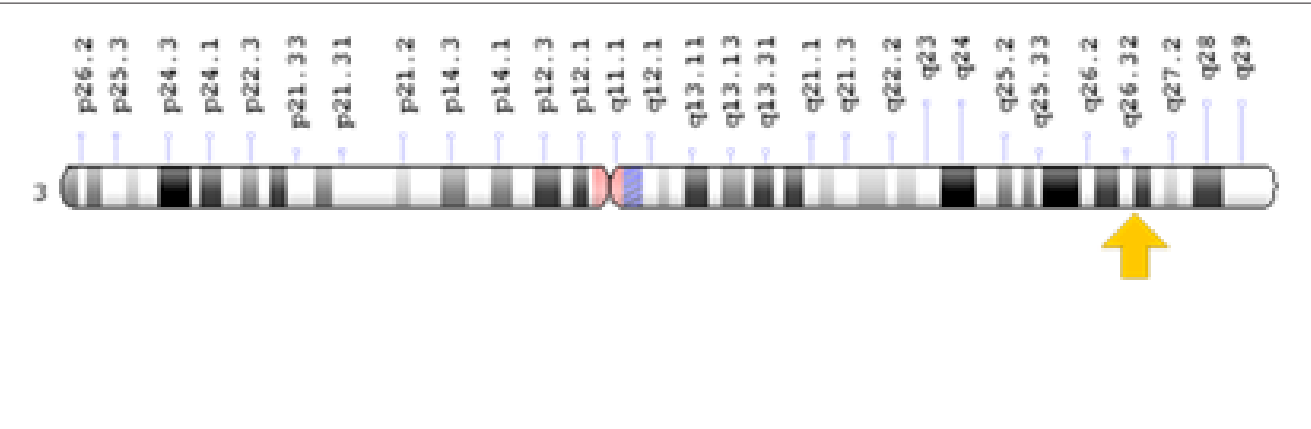

Figure 9: Schematic overview of chromosome 3 where the PIK3CA gene is located on the long arm of chromosome 3q26.32. 


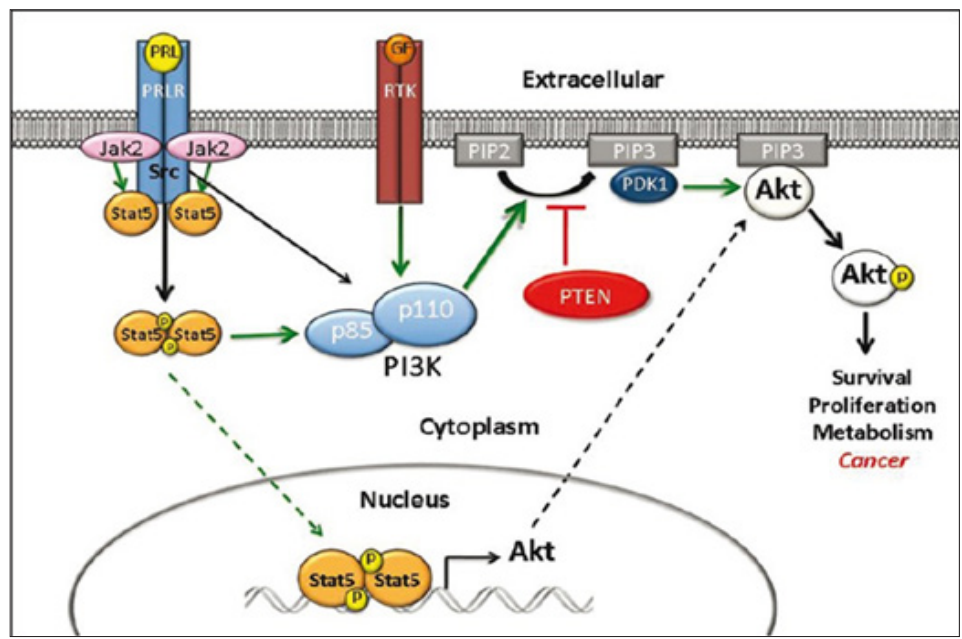

Figure 10: Schematic overview of the molecular mechanism of the AKT1 gene in cancer induction.

\section{Etiology of proteus syndrome}

Proteus syndrome is caused by a mosaic mutation of the AKT1 gene located on the long arm of chromosome 14 at $14 q 32.33$. The mutation occurs in the somatic cells of the fetus, and the researchers believe that this somatic mutation occurs by accident for no apparent reason. Some researchers have identified mutations in other genes, PTEN, located on the long arm of chromosome 10 as 10q23.31, and the GPC3 gene, which is located on the long arm of the X chromosome as Xq26.2, and PIK3CA on the long arm of chromosome No. 10.3 have been introduced as 3q26.32 based on Proteus Syndrome. However, in most cases, Proteus syndrome is caused by a mosaic mutation in the AKT1 gene $[1,9]$.

\section{Frequency of proteus syndrome}

Proteus syndrome is a very rare genetic disorder, of which only about 200 have been reported in the medical literature so far. It seems that Proteus Syndrome can affect all human races. Proteus syndrome affects men slightly more than women. Because Proteus
Syndrome is so difficult to diagnose, some people with this disorder may not be diagnosed or mistakenly diagnosed, making it difficult to determine the true frequency of Proteus Syndrome worldwide $[1,8]$.

\section{Diagnosis of proteus syndrome}

Proteus syndrome can be diagnosed using clinical diagnostic criteria published by the World Health Organization and the World Association of Human Genetics and Molecular Tests. Techniques such as biopsy of the tissues involved in this disorder, X-ray of the skeletal organs such as the spine, computed tomography of the skull, high-resolution CT scan of the lungs for pulmonary cyst examination and resonance imaging Magnetic resonance imaging (MRI) of the brain, abdomen, pelvis, organs, and ultrasound to detect scrotum or ovarian mass can also be helpful in the diagnosis of Proteus Syndrome Figures 11-13. The most definitive method for the diagnosis of Proteus Syndrome is molecular genetic testing for the AKT1 gene in the first priority and PTEN and GPC3 genes in the second priority to evaluate for the possible mutation [1,10-13].

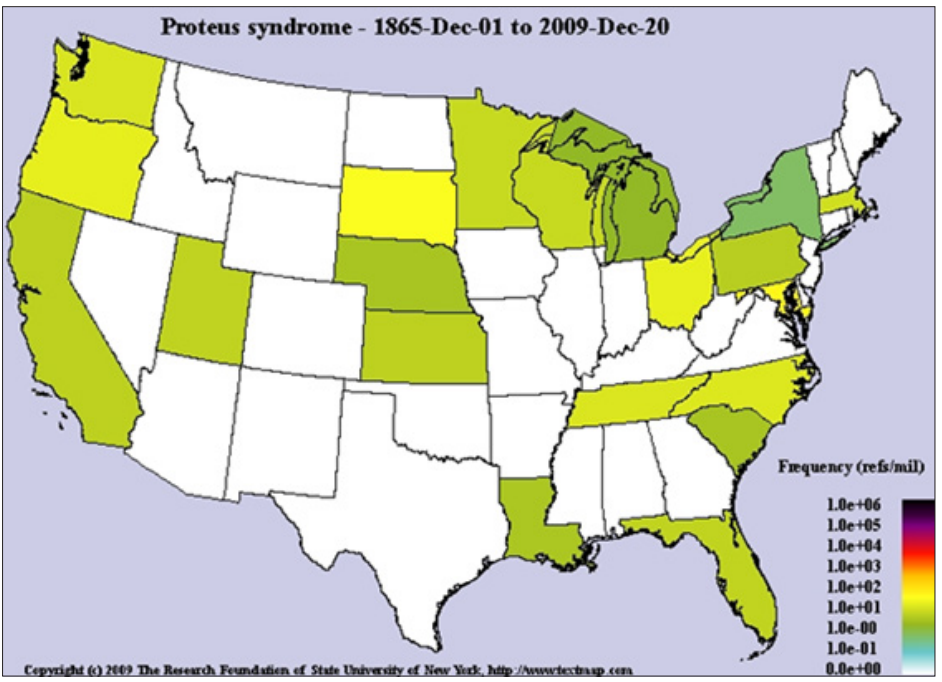

Figure 11: Schematic view of the frequency map of Proteus syndrome prevalence in the world. 


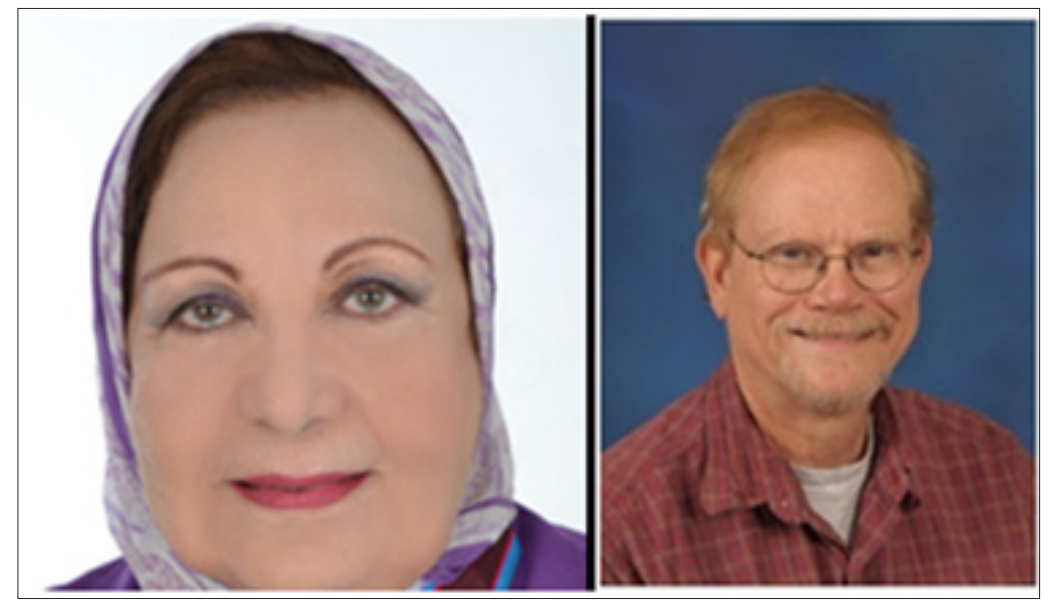

Figure 12: Pictures of Dr. Samieh Ali Tamtami (left) and Dr. John Rogers (right), Proteus Syndrome discoverers in 1976.

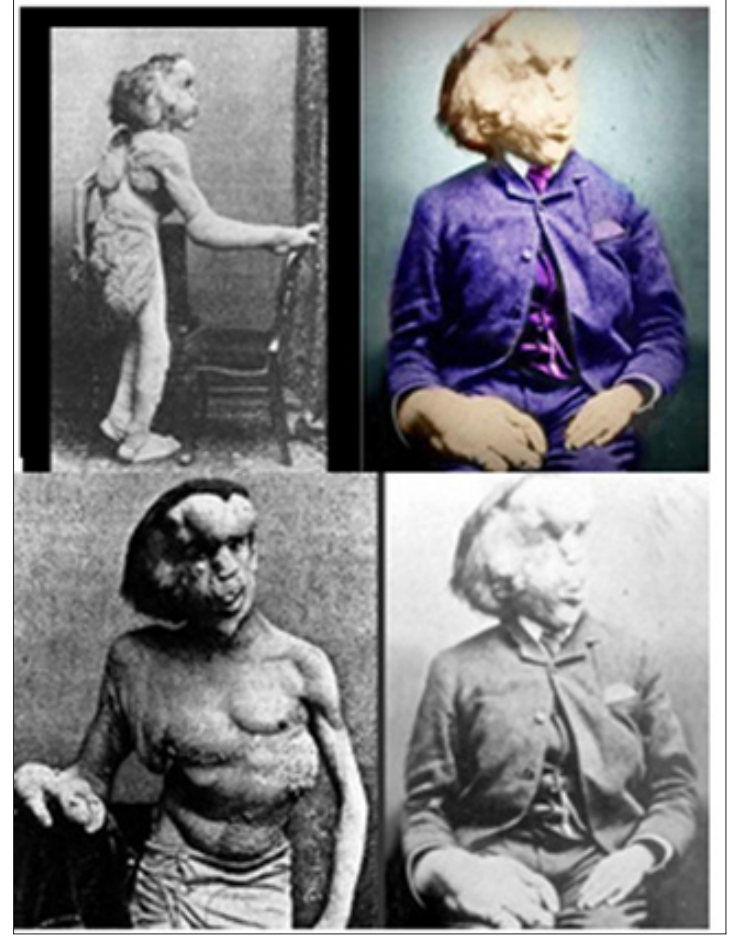

Figure 13: The oldest images found of a man named Joseph Gray of England from Proteus Syndrome who was known in his time as an elephant man.

\section{Therapeutic pathways of proteus syndrome}

Treatment of Proteus Syndrome is specific to the symptoms that appear in each person. Multiple orthopedic procedures may usually be helpful to control excessive and rapid bone growth. Surgery may also be helpful to improve the status of Proteus Syndrome patients with scoliosis. Epiphysiodesis technique, used to remove or erode bone growth plates, may be useful in preventing bone growth in patients with Proteus Syndrome. Genetic counseling is also essential for all families with a family history of genetic trauma, as well as for all families seeking healthy children $[1,8,14,15]$.

\section{Discussion and Conclusion}

Proteus syndrome is an extremely rare genetic disorder that is characterised by the abnormal growth of bones and blood vessels, and various skin lesions including lipomas, epidermal naevi and café au lait macules. The condition is usually not evident until late infancy or early childhood when signs and symptoms start to appear. Overgrowth of different body parts is progressive with time. Because Proteus syndrome is caused by AKT1 gene mutations that occur during early development, the disorder is not inherited and does not run in families. One name that has been 
proposed for the condition is segmental overgrowth, lipomatosis, arteriovenous malformations, and epidermal nevus (SOLAMEN) syndrome; another is type 2 segmental Cowden syndrome. However, some scientific articles still refer to PTEN-related Proteus syndrome[1,16,17].

\section{History of proteus syndrome}

Proteus syndrome was first reported in 1976 by Dr. Samieh Ali Tamatami of Egypt and Dr. John Rogers. In 1979, Dr. Michael Cohen also described more features of Proteus Syndrome. In 2013, a researcher named Mandy Sellars introduced the PIK3CA gene mutation in some of the cases of Proteus Syndrome [1,18].

\section{References}

1. Asadi S (2017) Pathology in medical genetics book. Amidi Publications, Iran.

2. Freedberg, Eisen AZ, Wolff K, Austen KF, Goldsmith LA, et al. (2003) Fitzpatrick's dermatology in general medicine $\left(6^{\text {th }}\right.$ edn), McGraw-Hill Education, USA.

3. Jamis-Dow CA, Turner J, Biesecker LG, Choyke PL (2004) Radiologic manifestations of proteus syndrome. Radiographics 24(4): 1051-1068.

4. Temtamy SA, Rogers JG (1976) Macrodactyly, hemihypertrophy, and connective tissue nevi: Report of a new syndrome and review of the literature. J Pediatr 89(6): 924-927.

5. Opitz JM, Jorde LB (2011) Hamartoma syndromes, exome sequencing, and a protean puzzle. N Engl J Med 365(7): 661-663.

6. Cohen MM, Hayden PW (1979) A newly recognized hamartomatous syndrome. Birth Defects Orig Artic Ser 15 (5B): 291-296.

7. Turner JT, Cohen MM, Biesecker LG (2004) Reassessment of the proteus syndrome literature: Application of diagnostic criteria to published cases. Am J Med Genet A 130A(2): 111-122.
8. Lindhurst MJ, Sapp JC, Teer JK, Johnston JJ, Finn EM, et al. (2011) A mosaic activating mutation in AKT1 associated with the proteus syndrome. N Engl J Med 365(7): 611-619.

9. Smith JM, Kirk EP, Theodosopoulos G, Marshall GM, Walker J, et al. (2002) Germline mutation of the tumour suppressor PTEN in Proteus syndrome. J Med Genet 39(12): 937-940.

10. Biesecker LG, Happle R, Mulliken JB, Weksberg R, Graham JM, et al. (1999) Proteus syndrome: Differential diagnosis, and patient evaluation. Am J Med Genet 84(5): 389-395.

11. Lindhurst MJ, Yourick, MR, Yi Yu, Ronald ES, Dora F, et al. (2015) Repression of AKT signaling by ARQ 092 in cells and tissues from patients with proteus syndrome. Sci Rep 5: 1-12.

12. Marsh DJ, Trahair TN, Martin JL, Chee WY, Walker J, et al. (2008) Rapamycin treatment for a child with germline PTEN mutation. Nat Clin Pract Oncol 5(6): 357-361.

13. Thiffault I, Schwartz CE, Der Kaloustian V, Foulkes WD (2004) Mutation analysis of the tumor suppressor PTEN and the glypican 3 (GPC3) gene in patients diagnosed with proteus syndrome. Am J Med Genet A 130A(2): 123-127.

14. Biesecker LG (2005) Proteus syndrome. In: Cassidy SB, Allanson JE (Eds.), Management of Genetic Syndrome. Wiley, New York, pp. 449-456.

15. Biesecker L (2003) Proteus syndrome. NORD guide to rare disorders, Lippincott Williams \& Wilkins, Philadelphia, PA, p: 239.

16. Biesecker L (2006) The challenges of proteus syndrome: Diagnosis and management. Eur J Hum Genet 14(11): 1151-1157.

17. Gordon PL, Wilroy RS, Lasater OE, Cohen MM Jr (1995) Neoplasms in proteus syndrome. Am J Med Genet 57(1): 74-78.

18. Slovotinek AM, Vacha SJ, Peters KF, Biesecker LG (2000) Sudden death caused by pulmonary thromboembolism in Proteus syndrome. Clin Genet 58(5): 386-389. 